\title{
Investigation on mixture design of one-part geopolymer from fly ash and water treatment sludge
}

\author{
Vuong $\mathrm{Ho}^{1}$, Aileen Orbecido ${ }^{1}$ and Michael A. Promentilla ${ }^{1 *}$ \\ ${ }^{1}$ Chemical Engineering Department, Gokongwei College of Engineering, De La Salle University, Manila, Philippines
}

\begin{abstract}
This study presents a one-part geopolymer system from coal fly ash and water treatment sludge. Geopolymer is typically produced from two parts namely the aluminosilicate solids, which is typically sourced out from industrial by-product, and an alkali activator solution which reacts with aluminosilicate solids to form an inorganic polymeric network. For a one-part geopolymer system, the solid binder with activators will just be added with water to address the drawback of corrosive and viscous alkali activator solution. Formulation of the proportion of geopolymer precursors with the two solid alkali activators namely sodium hydroxide and sodium aluminate was conducted using statistical mixture design. Effects of each components as well as interactions between them were evaluated by step-wise regression analysis. It was found that high alkali content decreased the compressive strength of binder. Meanwhile, the incorporation of sludge in this system helps reduce the unit weight of samples. Multiple response surface analysis that maximized compressive strength and minimized unit weight resulted in the optimal combination of $18.9 \%$ sludge, $76.1 \%$ fly ash and $5.0 \% \mathrm{NaOH}$.
\end{abstract}

\section{Introduction}

The shortage of raw materials for Ordinary Portland Cement (OPC) production and the stress of global warming urged many cement companies to find sustainable alternatives. In recent years, many efforts have been dedicated to replace OPC with coal fly ash (FA) in cementitious concrete. FA is a by-product from coal-fired thermal power plant. It contains large proportions of reactive silicate and aluminate that can be used as a geopolymer precursor which reacts with alkali activator solutions to form inorganic polymeric network [1]. The FA-based geopolymers have found to have superior strength for construction applications [2,3].

Water treatment sludge (WTS) is residue from water treatment plant. It is classified as non-hazardous waste and usually disposed to landfills. However, WTS has potential applicability on the manufacture of geotechnical materials [4,5]. For example, WTS was used as lightweight aggregate in FA-based geopolymer [6].

In this study, FA and WTS mixtures were activated by solid sodium hydroxide and sodium aluminate. The usage of solid activators creating a one-part geopolymer system could address the drawbacks of using corrosive and viscous alkali activator solution in a two-part geopolymer system [7]. Note that geopolymer is typically produced from two parts namely the aluminosilicate solids, which is typically sourced out from industrial by-product, and an alkali activator solution which reacts with aluminosilicate solids to form the hardened binder.

\section{Materials and Method}

\subsection{Materials}

Coal fly ash was collected from a certain power plant in Luzon, Philippines and used without any pre-treatment. The wet WTS was collected from a water treatment plant in Manila, Philippines. Wet sludge was dried at $105^{\circ} \mathrm{C}$ overnight then ground using an abrasion machine for 10,000 cycles. Anhydrous sodium hydroxide (99\% $\mathrm{NaOH})$ purchased from a local supplier in the Philippines and anhydrous sodium aluminate $(50-56 \%$ $\mathrm{Al}_{2} \mathrm{O}_{3} ; 40-45 \% \mathrm{Na}_{2} \mathrm{O}$ ) from Sigma-Aldrich were used as activators.

\subsection{Geopolymer synthesis}

Firstly, FA was mixed with WTS in mechanical mixer. Solid sodium hydroxide $(\mathrm{NaOH})$ and sodium aluminate $\left(\mathrm{NaAlO}_{2}\right)$ were added to raw materials and continuously blended for a minute. After that, water was poured into the solid mixture. The mixing was done for 10 to 30 minutes using a mechanical mixer. The paste was poured into $50 \times 50 \times 50 \mathrm{~mm}$ molds. Steel molds were greased beforehand for easier demolding. To prevent the 
Table 1. Compositions of two geopolymer mixtures.

\begin{tabular}{ccc}
\hline Component & Lower bound, \% & Upper bound, \% \\
\hline FA & 65 & 95 \\
WTS & 0 & 30 \\
$\mathrm{NaAlO}_{2}$ & 0 & 10 \\
$\mathrm{NaOH}$ & 5 & 15 \\
\hline
\end{tabular}

superficial carbonation of alkali activated samples, all of cubes were kept in plastic bags. Those were cured at ambient condition for 21 days before tested for compressive strength and unit weight.

\subsection{Design of Experiment - Mixture design and Multiple response surface analysis}

Mixture design is an optimization design of experiment in which all factors are the components of a mixture. Proportion of each component was varied within ranges as shown in Table 1. Sum of percentage of $\mathrm{NaAlO}_{2}$ and $\mathrm{NaOH}$ shall not exceed $15 \%$ based from the preliminary test. In the region of interest, 30 different combinations were chosen with an aim to fit the full cubic model:

$$
E(y)=\sum_{i=1}^{p} \beta_{i} x_{i}+\sum \sum_{i<j}^{p} \beta_{i j} x_{i} x_{j}+\sum \sum_{i<j}^{p} \delta_{i j} x_{i} x_{j}\left(x_{i}-x_{j}\right)+\sum \sum_{i<j<k} \sum \beta_{i j k} x_{i} x_{j} x_{k}
$$

To identify the point with the highest strength and
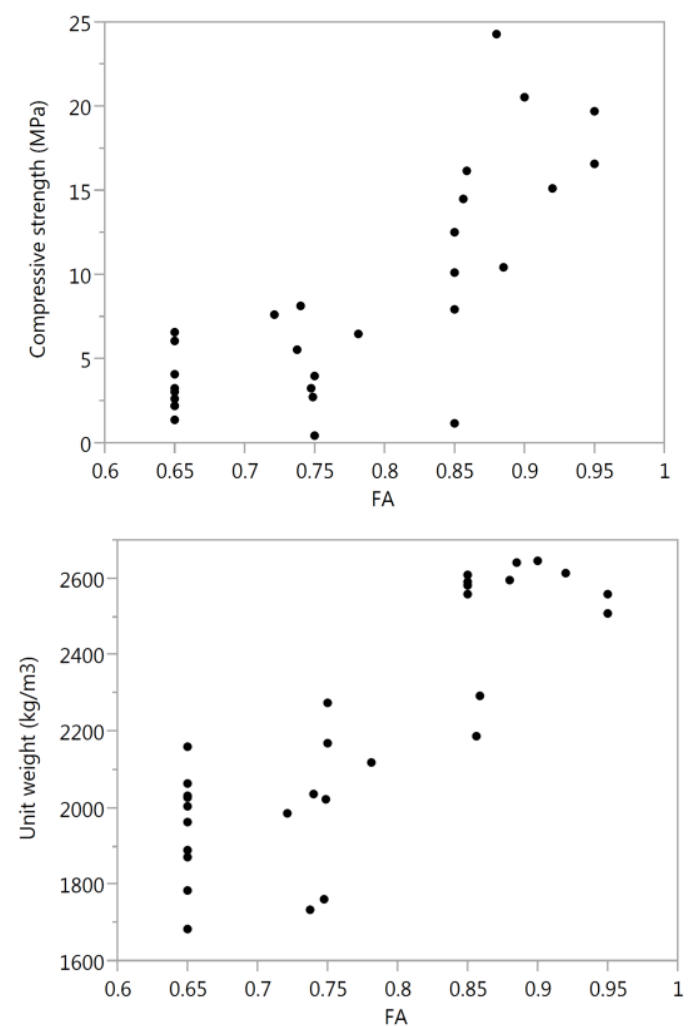

Fig. 1. Correlation between FA content and compressive strength and unit weight lowest weight, the multiple response surface analysis using desirability function was applied [8].

Desirability function $d_{i}$ is a transformation of the responses variable to a 0 -to-1 scale. Response of 0 represents a completely undesirable response and 1 represents the most desirable response. If all responses are evaluated equally, the overall desirability function is calculated as follow:

$$
D=\sqrt[m]{d_{1} d_{2} \ldots d_{m}}
$$

\subsection{Compressive strength test}

Unconfined compressive strength test was conducted in accordance with ASTM C109 standard [9]. Dimensions of specimens were firstly measured. Then, 50-mm cubes were tested using the Compression and Flexural Testing Machine at STRC, De La Salle University. Both surfaces exposed to the force were polished to avoid high deviation during the testing process. The loading speed was fixed at $0.35 \mathrm{kPa} / \mathrm{s}$. A computer was connected with the testing machine to record the result. Average of three replicates of each run was calculated.

\section{Results and discussion}

\subsection{Engineering properties results}

Figure 1 shows the trend of compressive strength and unit weight in correlation with variety of fly ash proportions. Generally, higher FA resulted in stronger
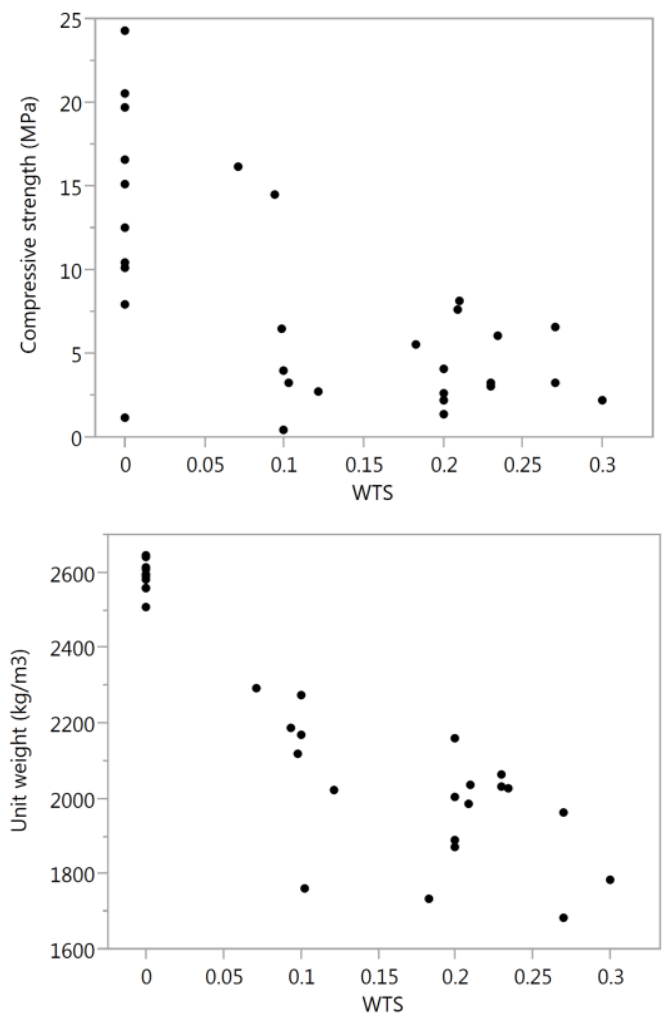

Fig. 2. Correlation between WTS content and compressive strength and unit weight 
one-part geopolymers with larger bulk density. Note that FA is a by-product of coal burning process, so it had been already thermally activated at high temperature. Therefore, higher dosage of FA increased proportion of reactive phases which increase the geopolymerization reaction rate and strengthen the geopolymer matrix. However, density of binder from FA is increased with concentration of precursor. On the other hand, the effect of WTS to the mixture is decreasing the bulk density of the geopolymer product. As noticed in Figure 2, the increase of WTS proportion leads to the reduction of unit weight of geopolymer. However, higher percentage of WTS reduced compressive strength of product. Without WTS, the binder could reach compressive strength above $20 \mathrm{MPa}$. Meanwhile, addition of $30 \%$ of sludge resulted in low-strength sample $(<5 \mathrm{MPa})$. It appears that WTS is relatively inactive and acts as lightweight aggregate in fly ash based gepolymer as observed in previous study [6].

\subsection{Multiple response analysis}

Experimental data in mixture design were fitted into regression models as follow:

$$
\begin{aligned}
\text { Compressive strength }= & 2.8854 *\left(\frac{W T S}{0.3}\right)+19.3089 *\left(\frac{F A-0.65}{0.3}\right)-54.3640 *\left(\frac{\mathrm{NaAlO}_{2}}{0.3}\right) \\
& -2.1453 *\left(\frac{\mathrm{NaOH}-0.05}{0.3}\right)+90.3054 *\left(\frac{\mathrm{WTS}}{0.3}\right) *\left(\frac{\mathrm{NaAlO}_{2}}{0.3}\right) \\
+ & 111.5347 *\left(\frac{\mathrm{FA}-0.65}{0.3}\right) *\left(\frac{\mathrm{NaAlO}_{2}}{0.3}\right) *\left(\frac{\mathrm{FA}-0.65}{0.3}-\frac{\mathrm{NaAlO}_{2}}{0.3}\right)
\end{aligned}
$$

$$
\begin{aligned}
\text { Unit weight } & =1823.769 *\left(\frac{W T S}{0.3}\right)+2633.647 *\left(\frac{F A-0.65}{0.3}\right)+2603.340 *\left(\frac{\mathrm{NaAlO}_{2}}{0.3}\right) \\
& +2160.139 *\left(\frac{\mathrm{NaOH}-0.05}{0.3}\right)-1056.761 *\left(\frac{\mathrm{WTS}}{0.3}\right) *\left(\frac{\mathrm{FA}-0.65}{0.3}\right) \\
- & 41703.112 *\left(\frac{\mathrm{NaAlO}}{0.3}\right) *\left(\frac{\mathrm{NaOH}-0.05}{0.3}\right) *\left(\frac{\mathrm{NaAlO}}{0.3}-\frac{\mathrm{NaOH}-0.05}{0.3}\right)
\end{aligned}
$$

Based on these predictive formulas, the prediction profiler was presented in Figure 3. Multiple response analysis resulted in the optimal composition of geopolymer which is $76 \% \mathrm{FA}, 19 \%$ WTS, $5 \% \mathrm{NaOH}$.
Optimal composition has compressive strength value of $8.98 \mathrm{MPa}$ that satisfies the requirement for non-load bearing units (4.14 $\mathrm{MPa}$ ) according to ASTM C129 standard [10]. Bulk density of the product is within the range for moderate-weight brick.

\section{Conclusions}

This study demonstrates that coal fly ash (CFA) and water treatment sludge (WTS) could be utilized in a onepart geopolymer binder for construction applications. Mixture design of experiment shows that FA is a good base material for geopolymerization as increased percentage of FA led to increase in compressive strength. Addition of WTS into the mixtures reduced unit weight of the binders but also reduce the compressive strength of the product. Multiple response analysis in which compressive strength was maximized and unit weight was minimized has given the optimal composition of $\mathrm{FA}=76 \%$, WTS $=19 \%, \mathrm{NaOH}=5 \%$ and sodium aluminate $=0$. The compressive strength and unit weight of optimal combination are $8.98 \mathrm{MPa}$ and $1877.7 \mathrm{~kg} / \mathrm{m} 3$ respectively.

\section{Acknowledgement}

The authors acknowledge the financial support of Japan International Cooperation Agency (JICA) through the AUN/SEED-Net scholarship.

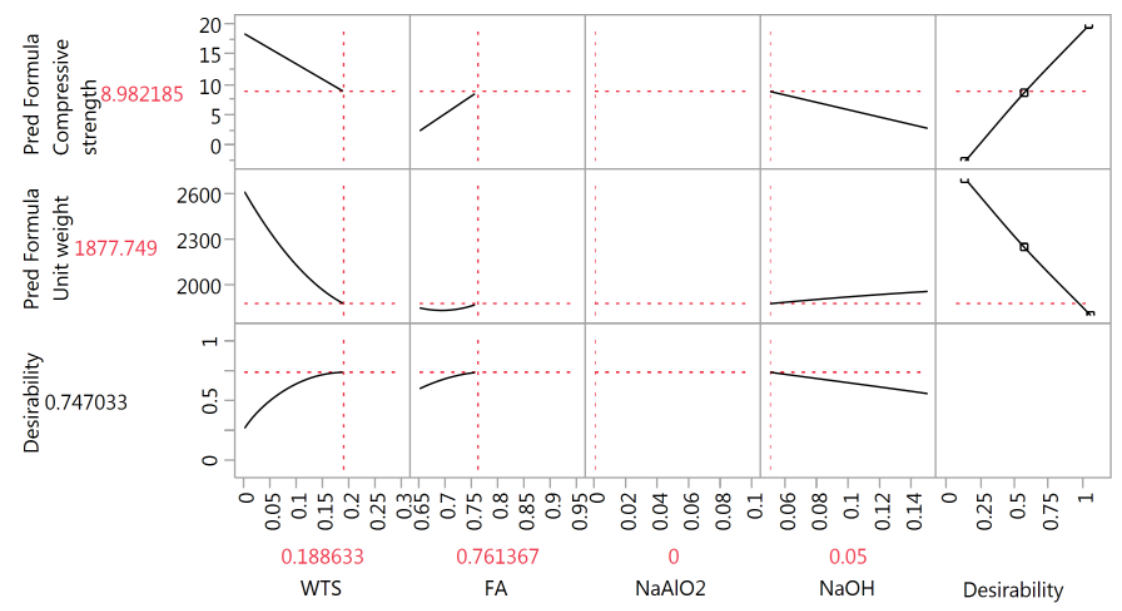

Fig. 3. Prediction profiler 


\section{References}

1. J. Davidovits, Geopolymer 2002 Conference (2002)

2. C.D. Atis, E.B. Görür, O. Karahan, C. Bilim, S. Ilkentapar, E. Luga, Construction and Building Materials, 96, 673-678 (2015)

3. G. Habert, C. Billard, P. Rossi, C. Chen, N. Roussel, Cement and Concrete Research, 40, 820-826 (2010)

4. S. Horpibulsuk, C. Suksiripattanapong, W. Samingthong, R. Rachan, A. Arulrajah, J. Mater. Civ. Eng, (2015)

5. E. Nimwinya, W. Arjharn, S. Horpibulsuk, T. Phoongernkham, A. Poowancum, Journal of Cleaner Production, 119, 128-134 (2016)

6. C. Suksiripattanapong, S. Horpibulsuk, S. Boongrasan, A. Udomchai, A. Chinkulkijniwat, A. Arulrajah, Construction and Building Materials, 94, 807-816 (2015)

7. B. Nematollahi, J. Sanjayan, F.U.A Shaikh, Ceramics International, (2015)

8. D.J. Obermiller, (n.d.). Multiple Response Optimization using JMP. The Dow Chemical Company, Midland, MI. Retrieved from http://www2.sas.com/inforvis/paper178

9. American Society for Testing Materials. Standard Test Method for Compressive Strength of Hydraulic Cement Mortars (Using 2-in. or [50-mm] Cube Specimens) (ASTM C109/109M - 16a). ASTM International, (2016)

10. American Society for Testing Materials. Standard Specification for Nonloadbearing Concrete Masonry Units (ASTM C129-14a). ASTM International, (2015) 